\title{
Effect of source of supplemental nitrogen on characteristics of digestion and utilization of Almond hulls-based diets by sheep
}

\author{
N Rihani, I Rbii \\ Institut Agronomique et Veterinaire Hassan II, BP 6202 Rabat Instituts, Maroc
}

\begin{abstract}
Almond hulls $(\mathrm{AH})$, a by-product of the almond crop (Prunus amygdalus) that includes the mesocarp and exocarp of the fruit, are widely available in the mediterranean region. This byproduct may be used as an energy source for ruminants, but it is deficient in $\mathrm{N}(6 \% \mathrm{CP})$ and contains relatively high levels of phenolic compounds ( $7 \%$ condensed tannins) which may interfere with $\mathrm{N}$ metabolism in the rumen. Effects of source of supplemental $N$ on characteristics of digestion and performance of lambs fed $\mathrm{AH}$-based diets were evaluated in 2 trials.
\end{abstract}

Four isonitrogenous ( $14 \% \mathrm{CP}$ ) diets containing (DM basis) $50 \% \mathrm{AH}$ and $25 \%$ alfalfa hay (17\% CP) were supplemented with either sunflower meal ( $38 \% \mathrm{CP}, A)$, urea (D), or combinations of both ( $B$ and $C$ ). Urea levels were $0,0.6,1.2$ and $1.7 \%$ in diets $A, B, C$ and $D$, respectively. As urea level was increased, sunflower meal was replaced by sugar beet pulp to equalize energy content of diets.

Trial I: Diets A, B and D were fed to 3 ruminally and intestinally cannulated rams (45 kg body weight) in a $3 \times 3$ latin square design experiment. Intake was limited to $0.8 \mathrm{~kg}$ $\mathrm{DM} /$ day. Chromic oxide was added to the diets $(0.5 \% \mathrm{DM})$ as digesta marker, and purines were used as microbial marker. Ruminal ammonia concentration increased with increasing urea, while ruminal $\mathrm{pH}$, ruminal and post-ruminal digestion of $\mathrm{OM}$ and fiber were not influenced $(P>0.05)$ by source of supplemental $N$. Net microbial $N$ synthesis (17 vs $14 \mathrm{~g} /$ day) and microbial efficiency ( 37 vs $29 \mathrm{~g}$ of microbial $\mathrm{N} / \mathrm{kg}$ OM truly fermented) were greater $(P<0.05)$ for $A$ than for $B$ and $D$. Nitrogen efficiency (duodenal non-ammonia $N /$ total $N$ intake) decreased $(P<0.05)$ with increasing urea level in the diet $(1.3,1.2$ and 1.1 for $A, B$ and $D$, respectively).

Trial II : Four balanced groups of 8 lambs (D'man x Sardi ; $21 \mathrm{~kg}$ and 4 months average initial weight and age) were randomly assigned to one of the 4 diets. Lambs were individually fed ad libitum for 98 days. Feed intake and daily gain decreased $(P<0.05)$ with increasing dietary urea level $(90.7,88.7,85.0$ and $79.2 \mathrm{~g}$

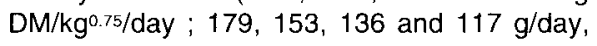
for $A, B, C$ and $D$, respectively). Feed efficiency also declined as urea level in the diet was increased $(7.1,7.4,7.8$ and $8.4 \mathrm{~kg} \mathrm{DM} / \mathrm{kg}$ gain for $A, B, C$ and $D$, respectively).

Although digestibility was not affected, non protein $\mathrm{N}$ (urea) was less efficient than natural protein for enhancing ruminal microbial protein synthesis and performance of lambs fed AH-based diets. 